\title{
EDUCAÇÃO PARA TRANSFORMAÇÃO: EMPODERAMENTO FEMININO ALICERÇADO NOS PRINCÍPIOS DA AGROECOLOGIA
}

\section{EDUCATION FOR TRANSFORMATION: FEMININE EMPOWERMENT BASED ON THE PRINCIPLES OF AGROECOLOGICAL}

\author{
VIEIRA, Márcia Gilmara Marian ${ }^{1}$ \\ IZA, Oscar Benigno ${ }^{2}$ \\ BORGES, Ana Carolina Gelschleiter ${ }^{3}$ \\ KORZ, Camila ${ }^{4}$
}

\begin{abstract}
RESUMO: O Projeto de Extensão Educação para Transformação: meio ambiente, saúde e gênero, surgiu com o propósito de diminuir o consumo de agrotóxico no município de Itajaí, Santa Catarina, por conta do efeito nocivo que gera aos organismos. O projeto visa o empoderamento das mulheres agricultoras do município de Itajaí, trabalhando em conjunto com seus parceiros, bolsistas e voluntários, realizando oficinas, rodas de conversas, saídas de campo e visitas técnicas nas propriedades das agricultoras. Sendo assim, é possível desenvolver a transição da agricultura convencional para a agroecológica. Essa intervenção objetiva adaptar as técnicas de produção na agroecologia, para proporcionar uma visão das dificuldades enfrentadas no cotidiano dessas mulheres, a partir disso é possível realizar o planejamento das atividades. Segundo relatos de agricultoras, o projeto tem proporcionado uma mudança na qualidade de vida, inclusão e autonomia das mulheres no mercado, valorização do trabalho camponês e familiar, saúde e bem-estar, além da pretensão de adquirir mais conhecimentos.
\end{abstract}

Palavras-chave: Agricultura orgânica. Empoderamento. Mulheres. Segurança alimentar.

ABSTRACT: The Extension Project "Education for Transformation: Environment, Health and Gender", aims at the empowerment of women farmers in the municipality of Itajaí, Santa Catarina, and works together with its partners, exhibitioners and volunteers, carrying out workshops, conversation circles, field trips, as well as technical visits at the farmers' houses. Thus, it is possible to develop a transition from conventional to agroecological agriculture. This intervention aims to adapt the production techniques in Agroecology, in order to provide a view of the difficulties faced daily by these women, and to promote the basis for the planning of the Workshops, with the purpose of

\footnotetext{
${ }^{1}$ Universidade do Vale do Itajaí, mmarian@univali.br

${ }^{2}$ Universidade do Vale do Itajaí, oscar@univali.br

${ }^{3}$ Universidade do Vale do Itajaí, anacarolinasjb@gmail.com

${ }^{4}$ Universidade do Vale do Itajaí, camila.korz@edu.univali.br
} 
assisting them in what they need most. In addition, that brings positive results, as now, for example, they sell their products. According to some women farmers, the Project has provided a change in their life quality, inclusion and autonomy, valorization of farmer and family work, health and well-being, and the pretension to acquire more knowledge.

Keywords: Empowerment. Organic Agriculture. Women. Nutrition Security.

\section{INTRODUÇÃO}

Finalizada a II Guerra Mundial em 1950, os países diretamente envolvidos no conflito armado estavam com suas economias falidas, mas ainda considerando os setores primários (agricultura e pecuária) e secundários (indústrias), não conseguiam fornecer os produtos necessários para suprir as necessidades básicas de sobrevivência da população, como alimentação, o que gerou a necessidade de criar um novo modelo de produção agropecuária, em grande parte reutilizando equipamentos e produtos químicos, naquilo que se conheceu como Revolução Verde (Bernal, 2015).

A Revolução Verde trouxe ganhos em produção e produtividade com tecnologias químicas e de equipamentos para produção em grande escala, além de envolver o uso maciço de fertilizantes e agroquímicos trazendo consequentemente, a médio e longo prazo projuízos ao solo, aos recursos hídricos, ao ambiente em geral, a agricultores e seus respectivos consumidores. Esta situação de desequilíbrio socioambiental tem apresentado índices alarmantes de redução da biodiversidade (flora e fauna) e elevado número de pessoas envolvidas na produção agrícola e pecuária manifestando diversas doenças agudas e crônicas. Também, deve ser lembrado que a aposta em alta produtividade e intensa mecanização tem provocado uma diminuição drástica na oferta de empregos e consequentemente êxodo rural em massa para a área urbana (Rosenzweig; Hillel, 2008).

O livro "Primavera Silenciosa" de Carson (1969, pag 252), traz consigo uma mensagem ética de alerta para os agrotóxicos: “a relação do homem com a natureza está no caminho errado e precisa mudar". O uso das substâncias químicas nas plantações está enfraquecendo as defesas inerentes do meio ambiente, como os insetos, esses agroquímicos podem ter tido pretexto de valer apenas contra algumas poucas espécies, porém não se leva em consideração todas as comunidades vivas que são atingidas.

O Brasil é, desde 2008, o maior consumidor de agrotóxicos do mundo. Segundo 
Carneiro et al. (2015), estima-se que cada brasileiro consuma uma média de 5,2 litros de agrotóxicos por ano, e muitos desses agrotóxicos utilizados no país foram banidos em outros países, devido à comprovação de seus efeitos por meio de órgãos legais, por casos de intoxicação aguda e crônica de trabalhadores e de pessoas que se alimentam de produtos contaminados por resíduos de agrotóxicos, além dos efeitos nocivos causados na cadeia alimentar.

Em 2013, foram consumidos $16 \mathrm{~kg} / \mathrm{ha}$ plantado, ou o equivalente a $6 \mathrm{~kg}$ per capita, no mesmo período (Brasil, 2016), destinados principalmente à produção de commodities agrícolas (Carneiro et al., 2015). No período de 2000 a 2012, as culturas de soja, milho e algodão contribuíram, em média, com mais de $60 \%$ dos agrotóxicos consumidos, números que se tornam ainda mais expressivos a partir da introdução das variedades transgênicas (Almeida et al., 2017). O registro histórico no uso de agrotóxicos na monocultura em soja, apresentou os seguites parâmetros: "aumento de 124\%, enquanto a produtividade (toneladas/hectare) cresceu apenas 9,5\%," estes valores mostram claramente a discrepância entre produção e produtividade contrariando o equilíbrio ecossitêmico, onde este modelo econômico visa produzir commodities do que alimentos para a sociedade. Esta situação gerou uma série de contestações por trazer danos ao ambiente, as pessoas envolvidas e cujo os resultados está muito mais alinhado a exportação do que para o consumo do mercado interno (Greenpeace Brasil, 2017).

Diante dessas tendências globais, os conceitos de soberania alimentar e sistemas de produção, baseados na agroecologia, ganharam muita atenção nas duas últimas décadas. Iniciativas apontam que a aplicação da ciência agroecológica moderna, alimentada por sistemas de conhecimento indígena, liderada por milhares de agricultores, por organizações não governamentais e por algumas instituições governamentais e acadêmicas, pode melhorar a segurança alimentar, preservando os recursos naturais, a agrobiodiversidade, e também a conservação do solo e da água em centenas de comunidades rurais de várias regiões (Pretty; Morrison; Hine, 2003, p. 217234).

Para reverter o modelo de agricultura convencional, produtivista e de injustiças sócio ambientais adotados após a Revolução Verde, a agricultura sustentável e a agroecologia apresentam-se como uma forma de resgatar os saberes populares e 
tradicionais, e esses dois segmentos têm como propósito trabalhar e alimentar sistemas agrícolas complexos, além de estabelecer interações ecológicas e sinergismos entre os componentes biológicos para que propiciem a fertilidade do solo, a produtividade e a proteção das plantas (Dalrot, 2002 apud Vieira, et al, 2016)

Considerando as premissas acima descritas, o Projeto de Extensão "Educação para Transformação: meio ambiente, saúde e gênero", tem como objetivo primordial a educação continuada em saúde, meio ambiente, relações de gênero para o transformação social, econômica e ambiental da agricultura familiar, proporcionando a ativa participação cidadã como estrutura social de mudança, independência, alternativa de renda local, estímulo ao consumo de alimentos saudáveis e qualidade de vida mediada pela agricultura de base agroecológica de mulheres agricultoras do município de Itajaí, Santa Catarina. Como objetivos complementares propõem-se articular e integrar políticas públicas, programas e ações geradoras da transição agroecológica e da produção orgânica no grupo de mulheres agricultoras, induzindo desta forma uma progressiva mudança de manejo do sistema agroecológico, procurando a resiliência natural e justiça social (Vieira, 2017).

O referido Projeto de Extensão é vinculado à Universidade do Vale do Itajaí (UNIVALI), a qual é norteada pelo tripé: ensino, pesquisa e extensão, e está alicerçado nos princípios da Lei 12.305/2010 que institui a Política Nacional de Resíduos Sólidos - PNRS (BRASIL, 2010). Por fomentar a valorização da fração orgânica dos resíduos, pelo processo de compostagem. O Projeto também tem como base a nova Agenda de Desenvolvimento Sustentável da ONU, abrangendo os Objetivos de Desenvolvimento Sustentável (ODS), tais como: erradicação da pobreza, fome zero e agricultura sustentável, saúde e bem-estar, igualdade de gênero, redução das desigualdades, cidades e comunidades sustentáveis, consumo e produção responsáveis, ação contra a mudança global do clima e da vida terrestre.

Além desses, o Projeto ainda é estabelecido pela Lei $n^{\circ}$ 11.326/2006 que institui a Política Nacional da Agricultura Familiar e Empreendimentos Familiares Rurais (BRASIL, 2006), mediante os princípios instituídos por modelos de descentralização, sustentabilidade ambiental, social e econômica, equidade na aplicação das políticas, respeitando aspectos de gênero, geração e etnia, observando as diferentes tradições, concepções e experiências constituídas pelos agrupamentos humanos, na pluralidade de 
canais para o diálogo, e na troca de conhecimento entre os grupos sociais. Ademais, busca valorizar a multifuncionalidade da agricultura familiar e dos territórios rurais, a fim de compreender os espaços rurais em suas dimensões socioculturais e simbólicas, e não apenas enquanto provedores de alimentos ou de serviços ambientais.

Nesse sentido, este é o relato das ações desenvolvidas no ano de 2017 pelo Projeto de Extensão Educação para Transformação, com as mulheres agricultoras do município de Itajaí, Santa Catarina. Trata-se de uma proposta interdisciplinar com a participação de três centros vinculados à Universidade: 1. Escola do Mar, Ciência e Tecnologia, 2. Escola de Ciências da Saúde e 3. Escola de Negócios, que busca articular o tripé ensino, pesquisa e extensão. A extensão forma um dos alicerces da Universidade e se torna relevante para a consolidação dos Projetos Pedagógicos dos cursos envolvidos.

Dessa forma, torna-se imprescindível contribuir com informações e mudanças de paradigmas para as mulheres agricultoras do município de Itajaí que se expõem aos agrotóxicos e, ainda, por falta de conhecimento, contribuem para contaminar solos, atmosfera, alimentos, águas superficiais e lençóis freáticos, além de toda a biodiversidade. O público principal justifica-se pelo fato de que as mulheres estão preocupadas com a saúde de sua família, e por isso aceitam as mudanças da educação para a transformação como uma alternativa de melhorar a saúde, qualidade de vida e também de obter renda dentro da sua propriedade, permitindo-lhes maior autonomia profissional. Além disso, a escolha desse público aconteceu pelo fato de as mulheres possuírem maior cuidado com o meio e não priorizarem somente o fator econômico. Com isso, essa mudança da mulher agricultora, dentro da agroecologia, está se tornando uma realidade para a agricultura sustentável, e a equipe do Projeto de Extensão tem observado essa evolução na agroecologia.

As Oficinas desenvolvidas com o público-alvo, no Projeto de Extensão, têm priorizado as temáticas sugeridas pelas mulheres agricultoras a partir das dificuldades encontradas no dia a dia. Acredita-se que as atividades possibilitam conhecimento e informação, permitindo a construção de uma rede dentro da Agroecologia, além de estimular a comunidade a participar mais ativamente do seu cotidiano.

Os resultados demonstraram que das temáticas trabalhadas com as mulheres, aquelas que trouxeram aprendizados transformadores foram as seguintes: o Controle 
Biológico de Insetos, a Composteira de Leira, o Bokashi, e o conhecimento das Plantas Alimentícias Não Convencionais (PANC).

Com isso, salienta-se que a metodologia utilizada foi adequada ao público-alvo, tendo impacto positivo na formação do conhecimento e no fortalecimento de uma postura crítica e reflexiva, responsável e comprometida com a produção de alimentos saudáveis, priorizando o cuidado com a saúde e com o meio ambiente.

No presente momento o projeto se encontra na sua quarta etapa, onde os objetivos e metas, possuem o desenvolvimento de um ano, e os dados e resultados aqui constados se referem aos três anos do projeto.

\section{MÉTODOS}

Baseada nos pressupostos de Paulo Freire, a metodologia é inspirada no Círculo de Cultura. Sistematizados por Paulo Freire (1991), os Círculos de Cultura estão fundamentados em uma proposta pedagógica, cujo caráter, radicalmente democrático e libertador, propõe uma aprendizagem integral, que rompe com a fragmentação e requer uma tomada de posição perante os problemas vivenciados em determinado contexto. Para Freire, essa concepção promove a horizontalidade na relação educador-educando e a valorização das culturas locais da oralidade, contrapondo-se em seu caráter humanístico à visão elitista de educação.

As estratégias de ação do Projeto de Extensão no ano de 2017 se concentraram na realização de diversas atividades que serão apresentadas no decorrer dessa metodologia.

É necessário destacar as parcerias existentes dentro do projeto, quais sejam: Secretaria da Agricultura do Município de Itajaí, Rede Ecovida, EPAGRI, entre outras, visando aproximação à realidade do público-alvo. Essas parcerias são importantes para as oficinas, pois é com o auxílio delas que surgem os profissionais técnicos de cada área específica, dentro da Agroecologia e da Saúde. No primeiro momento, realizou-se reunião com parceiros do Projeto, para o planejamento a ser executado durante o ano de 2017.

São realizadas, quinzenalmente, oficinas para as mulheres agricultoras e para o Grupo de Estudos Interdisciplinares de Agroecologia e Produção Orgânica (GEIA) com diferentes temáticas. As oficinas são planejadas e preparadas pela coordenadora, com a 
ajuda e a execução de bolsistas integrantes do Projeto de Extensão.

O público-alvo já vem participando do Projeto há três anos, por isso essas pessoas têm autonomia para escolher os "temas" que são levantados no cotidiano de trabalho. A busca de tema ou palavra geradora, isto é, aquela extraída do universo do cotidiano dos educadores e mulheres agricultoras, é o miolo do método, geralmente está localizada em círculos concêntricos, que partem do mais geral ao mais específico (Freire, 1983; Gadotti, 1991).

Essas oficinas são estruturadas da seguinte forma: "Dinâmica", "Desenvolvimento da temática de forma expositiva, problematizadora e participativa", "Café Solidário" e "Socialização de Encerramento". Foram realizadas oito oficinas, teórico/prática, com duração de quatro horas (240 min.) cada, abrangendo os temas:

1. Organização do grupo de mulheres agricultoras na Rede Ecovida; 2. Compostagem; 3. Controle e Manejo de Insetos, Fungos e Doenças, através de Bioinseticidas e Herbicidas Naturais; 4. Coleta e Identificação de Controle Biológico em Plantas; 5. Gestão de Produtos Orgânicos e Participação em Feiras Agroecológicas; 6. Plantas Alimentícias Não Convencionais (PANC); 7. Sistemas Agroflorestais (SAFs); 8. Plantas Medicinais; 9. Hortas urbanas. Essas reuniões foram desenvolvidas nas dependências da Universidade do Vale do Itajaí, nas propriedades das mulheres agricultoras e na Associação da Rede Ecovida.

Assim, sob essa óptica, foram desenvolvidas as atividades com o público-alvo do Projeto, tendo por intuito ampliar seus saberes sobre a agroecologia e continuar aplicando seus conhecimentos nas produções e na formação como cidadão com consciência ambiental. Esses procedimentos de controle natural foram escolhidos por serem os mais ecoeficientes, baratos e sustentáveis, premissas fundamentais da agroecologia, se for considerado o ecossistema de modo integrado.

Também foram realizadas como estratégias de formação as visitas técnicas a propriedades de agricultores agroecológicos que têm Certificação Orgânica, e na Empresa de Pesquisa Agropecuária e Extensão Rural de Santa Catarina (EPAGRI), que tem modelo de agricultura sustentável e desenvolvimento de tecnologias para a produção orgânica. As visitas tiveram o intuito de incentivar a produção de alimentos sem a utilização de agrotóxicos; conhecer as pesquisas, experiências e métodos utilizados para a agricultura sustentável; destacar a importância de resguardar áreas de 
preservação permanente - APP's e unidades de conservação; explorar os cultivos das plantas alimentícias não convencionais (PANC) e plantas medicinais para consumo e utilização nutracêutica e a produção de alimentos orgânicos; conhecer experiências práticas de Sistemas Agroflorestais Sintrópicos.

No decorrer do ano, aconteceram visitas para assistência técnica nas propriedades das mulheres agricultoras participantes do Projeto, local em que são feitas as avaliações de suas produções e dos cultivares, com a aplicação de questionários semiestruturados para a atualização dos dados.

Nesse contexto, o Projeto também realizou inúmeras "Rodas de Conversa" com uma metodologia transformadora tanto para a equipe, público-alvo e os diferentes participantes. No quadro 1, são apresentados as temáticas das rodas de conversas realizadas pelo projeto, os públicos atingidos foram as mulheres participantes do projeto, acadêmicos e professores de diversos cursos da UNIVALI, produtores rurais, grupo de hipertensos e membros da comunidade.

\begin{tabular}{|l|l|l|}
\hline Temática & Participantes & Ocasião e Local \\
\hline $\begin{array}{l}\text { Educação para Transformação: } \\
\text { a importância da agroecologia na } \\
\text { vida das mulheres agricultoras de } \\
\text { Itajaí/SC" }\end{array}$ & 105 pessoas & $\begin{array}{l}\text { Biblioteca Central/UNIVALI } \\
\text { Itajaí/SC }\end{array}$ \\
\hline Saúde da Mulher Rural & 115 pessoas & Araquari/SC \\
\hline $\begin{array}{l}\text { PANC e plantas medicinais } \\
\text { Alimentação Saudável, alerta aos } \\
\text { Agrotóxicos e PANC }\end{array}$ & 27 pessoas & $\begin{array}{l}\text { Sítio Flora Bioativas } \\
\text { Porto Belo/SC }\end{array}$ \\
\hline $\begin{array}{l}\text { Apresentação do Projeto de Extensão } \\
\text { Educação para Transformação, e } \\
\text { troca de saberes e experiências das } \\
\text { mulheres agricultoras participantes } \\
\text { do Projeto }\end{array}$ & 122 pessoas & $\begin{array}{l}\text { Comunidade de Espinheiros } \\
\text { Itajaí/SC }\end{array}$ \\
\hline
\end{tabular}




\begin{tabular}{l|l|l|}
$\begin{array}{l}\text { Mulheres Agricultoras: autonomia e } \\
\text { empoderamento }\end{array}$ & 35 pessoas & $\begin{array}{l}\text { Exposição "É preciso ter } \\
\text { força” } \\
\text { UNIVALI/SC }\end{array}$ \\
\hline
\end{tabular}

Quadro 1: Temáticas das Rodas de conversa realizadas pelo Projeto de Extensão Educação para Transformação.

Dentro desse enfoque e com o objetivo de disseminar o trabalho realizado pelo Projeto, por meio da produção de materiais científicos e relatos de experiência, a Equipe do Projeto e algumas mulheres representantes participaram de eventos externos como: 1. Palestra Internacional de Agroecologia; 2. Fórum Integrado de Extensão na UNIVALI; 3. Ciclo de Palestras Guabiruba: planejar e conservar é preciso; 4. IX Fórum Brasileiro de Educação Ambiental - IX FBEA e IV Encontro Catarinense de Educação Ambiental - IV ECEA; 5. $11^{\circ}$ Mostra Integrada de Ensino, Pesquisa, Extensão e Cultura - MIPE; 6. VI Congresso Latino-Americano de Agroecologia, X Congresso Brasileiro de Agroecologia e o V Seminário de Agroecologia do Distrito Federal e Entorno; 7. Opção Profissional por Área - OPA - UNIVALI; 8. Seminário Estadual de Agroecologia em Santa Rosa de Lima - SC; 9 Congresso Internacional de Políticas Públicas; 10. II Simpósio Internacional de Promoção da Saúde.

Esses pressupostos norteiam a metodologia utilizada junto com as famílias de agricultores no município de Itajaí para o alcance dos objetivos do Projeto. Vale ressaltar que acadêmicos e pesquisadores envolvidos, são ao mesmo tempo agentes de mudança e sujeitos a serem "transformados", no dizer de Paulo Freire.

\section{RESULTADOS E DISCUSSÃO}

Os dados levantados, a partir das atividades realizadas no Projeto, trouxeram resultados importantes para a construção de conhecimentos e transformação dos participantes. Tais conhecimentos foram assimilados a partir dos conteúdos trabalhados nas oficinas, nas visitas técnicas, nos eventos científicos e também nas formações do Projeto de Extensão para o público-alvo.

A formação do grupo de mulheres agricultoras é consolidada por meio do aprimoramento das técnicas de manejo, bem como pela valorização de trocas mútuas de experiências teóricas e empíricas, adquiridas pelas agricultoras, durante esse trajeto. As atividades oferecidas nas oficinas buscam constantemente o aperfeiçoamento dos 
conhecimentos das mulheres agricultoras, visando a uma autonomia do planejamento de suas propriedades e da execução das ações de intervenção sobre alguma intempérie.

Desse modo, pretende-se garantir que os temas abordados tenham relação, de forma direta, com os desafios enfrentados e que as soluções ofertadas tenham as mulheres agricultoras como protagonistas dessas ações.

A primeira atividade de 2017, foi a participação da equipe do Projeto e as mulheres agricultoras na reunião mensal da Rede Ecovida de Joinville/SC, que teve como intuito apresentar o processo de Certificação Participativa. Nessa ocasião, discutiu-se sobre os documentos e as práticas necessárias para que fosse formado o grupo da Rede Ecovida, em Itajaí. Essa temática despertou o interesse do grupo de mulheres agricultoras, pois a Certificação Participativa tem o intuito de agregar mais valor aos produtos comercializados. Essa é adequada para as mulheres agricultoras, pois trata de um processo de certificação da produção dos alimentos orgânicos e é organizada por integrantes da Rede Ecovida.

A Certificação Participativa vem com um propósito particularizado, objetivando a valorização dos produtos ecológicos, por meio do trabalho em grupo, buscando a sustentabilidade ecológica das propriedades e o aprofundamento dos conhecimentos e fundamentos da agroecologia (Rede de Agroecologia ECOVIDA, 2004).

A certificação é, antes de tudo, um instrumento pedagógico para motivar e articular os diversos atores. Todos os integrantes da rede que tomam parte de uma certificação têm internalizado os seus procedimentos, sendo o objetivo em si a organização do movimento e a sua autonomia. Essa metodologia estimula a integração entre agricultores e consumidores, bem como a organização social em uma lógica de rede, na qual a relação que se estabelece é horizontal e de interdependência (não favorecendo hierarquias), essa parte de relações de confiança (Tygel; Motta, 2011).

No encontro das mulheres agricultoras de Itajaí, que aconteceu mensalmente, nas oficinas do Projeto, as mulheres já estavam com o grupo organizado, mas elas ainda precisavam, para viabilização do processo de certificação, formar o Núcleo Regional de Itajaí e montarem o Conselho de Ética para a efetivação do grupo na Rede Ecovida.

Portanto, ara formação do Conselho de Ética é necessário a participação de agricultor , técnico e consumidor que atenda cada núcleo regional conforme exigência do processo de Certificação Participativa (Oliveira; Santos (Cord.), 2004, pag 40). 
Outra meta importante do Projeto é o processo de formação continuada das mulheres agricultoras, baseado em técnicas de manejo, em cultivo e práticas da agricultura de base agroecológica, buscando alcançar as características semelhantes aos de agroecossistemas naturais. Estes têm também como propósito a diversidade de estratégias de produção, visando minimizar a necessidade de recursos externos e o acesso a mercados, à organização social e à luta pela autonomia social, política e cultural dessas mulheres.

Uma temática de grande envergadura e que foi exaustivamente trabalhada, diz respeito à compostagem, na qual existem várias técnicas possíveis, porém a mais utilizada pelas agricultoras é o Bokashi, um adubo orgânico fermentado, cujos nutrientes se obtêm a partir do calor originado durante sua preparação. Esse tipo de adubo tem sido muito utilizado, apresentando excelentes resultados, já que os ingredientes podem ser modificados conforme a disponibilidade e as condições do lugar. Por outro lado, é importante ensinar o processo e sua preparação, bem como destacar a função de cada componente da fórmula (Rede de Agroecologia ECOVIDA, 2015).

Além disso, outra técnica utilizada é a Composteira de leira, conforme observado figura 01, composteira realizada na Horta Orgânica Experimental - Ibyporã da UNIVALI, pelo GEIA. O lixo orgânico constituído de restos de alimentos, bagaços, cascas de frutas e legumes é o principal material usado na formação da leira. Esse substrato orgânico contém concentração adequada de nutrientes, principalmente o nitrogênio, para a compostagem (Teixeira et al., 2004). 


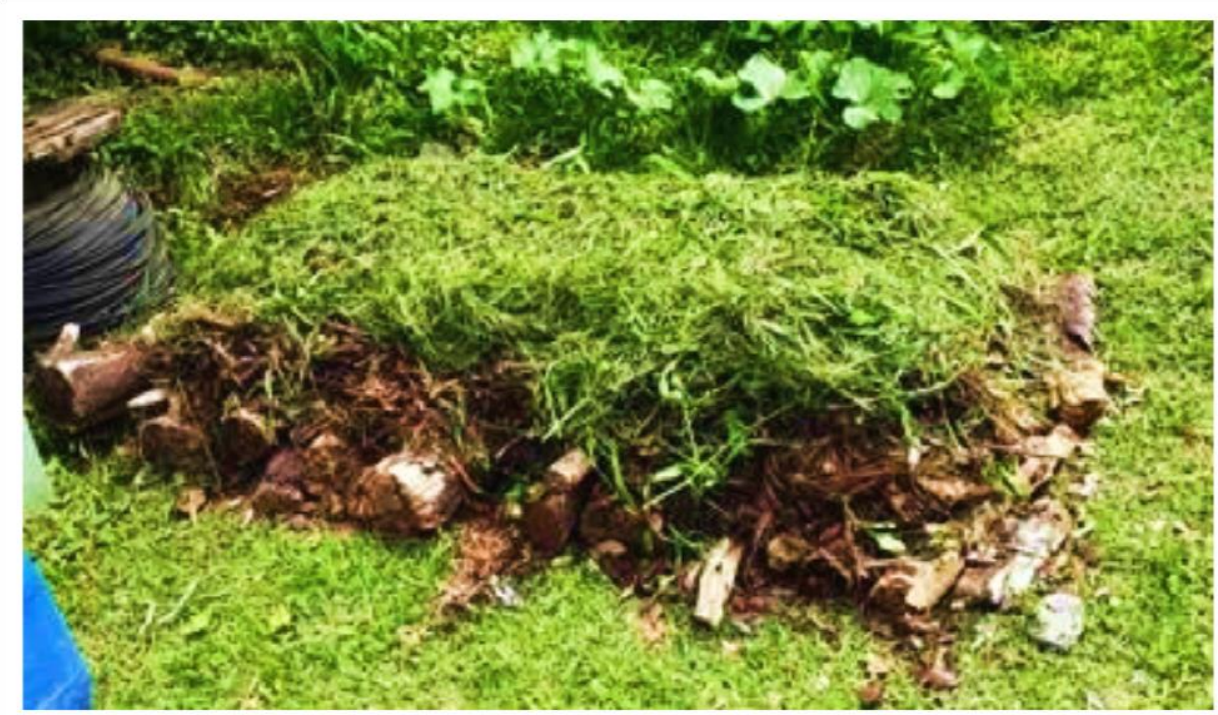

Figura 1: Composteira de leira realizada na Horta Orgânica Experimental - Ibyporã da UNIVALI. Fonte: Arquivo pessoal do autor.

Além do lixo orgânico, adicionam-se outros substratos orgânicos encontrados nas propriedades, tais como: capim, folhas secas e serragem - fontes ricas em carbono para ajuste da relação carbono/nitrogênio, como também para melhorar a estrutura física da leira. "As leiras de compostagem devem ser formadas, inicialmente, com cerca de $30 \%$ de lixo orgânico, logo após a separação do material, 70\% de capim, folhas e serragens, arrumados em camadas" (Teixeira et al., 2004, p.8).

As mulheres agricultoras aprenderam com os métodos de compostagem que podem aproveitar ao máximo e valorizar a fração orgânica dos resíduos que são produzidos em suas casas e hortas. Uma das agricultoras, participante ativa do Projeto, relata: "Hoje com tudo que eu aprendi no Projeto, já consigo produzir para meu consumo próprio e para a venda no mercado; minha horta se autossustenta com a produção de adubo, com os restos de comidas, de folhas e de frutas que sobram das colheitas, e tudo isso foi um conhecimento que eu aprendi, pois podemos reaproveitar tudo e ajudar a manter o meio ambiente saudável". Ela comenta ainda que: "Antigamente eu não tinha conhecimento dos malefícios que o uso dos agrotóxicos e dos adubos químicos poderia causar à saúde e ao meio ambiente, pois como minha horta era pequena, eu não utilizava veneno, e sim, ureia e adubos". E continua: "Foi com o Projeto que aprendi a utilizar a própria natureza a meu favor e manter o meio ambiente saudável e em equilíbrio. Hoje em dia, percebo que o meu trabalho é 
reconhecido, tendo em vista que as pessoas dão mais valor para alimentos sem agrotóxicos".

Outra temática que obteve resultados satisfatórios foi o ensino de bioinseticidas naturais para o controle e o combate de insetos que afetam a produtividade. Os insetos são indicadores de desequilíbrio no sistema de produção de base agroecológica e fazem parte da natureza. Normalmente, esse desequilíbrio é provocado pela ação do homem, com a prática incorreta de adubação e manejo inadequado das culturas, práticas de queimadas; com a monocultura e com o uso de agrotóxico, e isso faz com que alguns desses insetos se multipliquem rapidamente, aliados a fatores climáticos que favorecem seu crescimento, reduzindo seus ciclos de reprodução e tornando-se uma infestação no cultivo, além de quebrar a cadeia de inter-relação animais/animais e animais/plantas. Em virtude disso, aplicar inseticidas e fungicidas naturais é uma maneira de ajudar a evitar maiores danos, todavia não é a única, as aplicações devem estar relacionadas ao manejo do solo e das culturas, fazendo uma boa adubação orgânica, mantendo uma cobertura morta e realizando a rotação e o consorciamento de culturas (Zamberlam; Froncheti, 2012 apud Ferreira, 2015).

Na Oficina de "Produção dos Bioinseticidas e Herbicidas Naturais" que ocorreu em duas etapas: a primeira foi realizada no Laboratório de Química Orgânica da UNIVALI, e a segunda foi realizada na propriedade de uma das mulheres agricultoras, no Bairro Paciência. As duas etapas foram ministradas pelo Coordenador da Rede Ecovida, que é um dos parceiros do Projeto.

A atividade foi dividida em duas etapas: teórica e prática, sendo que na primeira foram ensinadas, passo a passo, as receitas, as vantagens, a função, bem como o modo de utilização; e, na segunda, todos tiveram a oportunidade de desenvolver as receitas, manipular cada um dos ingredientes, e levar uma amostra dos bioinseticidas.

O interessante da prática é que as mulheres agricultoras e os acadêmicos vivenciaram a técnica repetidamente, utilizando os instrumentos e os equipamentos disponíveis no Laboratório de Química da UNIVALI, e depois os equipamentos disponíveis na propriedade da agricultora.

Dessa forma, os participantes aprofundaram os seus conhecimentos para a produção dos bioinseticidas, como por exemplo: Calda Bordalesa (fungicida). Informações técnicas: não usar na fase de floração (abortiva); e não fazer mais que 4 
aplicações por cultivo. Ingredientes: $200 \mathrm{~g}$ de sulfato de cobre; $200 \mathrm{~g}$ de cal virgem; 201 de água. Modo de preparo: Preparar a solução de sulfato de cálcio com 101 de água e, separadamente, a solução de cal com 101 de água, depois misturar as duas soluções. Utilização e dose: $600 \mathrm{ml}$ da calda bordalesa diluída em 201 de água (hortaliças) a cada 15 a 20 dias uma aplicação; e para frutíferas 11 ou 21 diluídos em 201 de água a cada 30 a 40 dias uma aplicação.

Outro exemplo, Bioinseticida de cebola e alho: usado para pulgões. Ingredientes: 3 cebolas $+1 / 2$ cabeça de alho. Modo de preparo: Bater tudo no liquidificador com casca em 11 de água. Utilização e dose: 11 diluir em 101 de água.

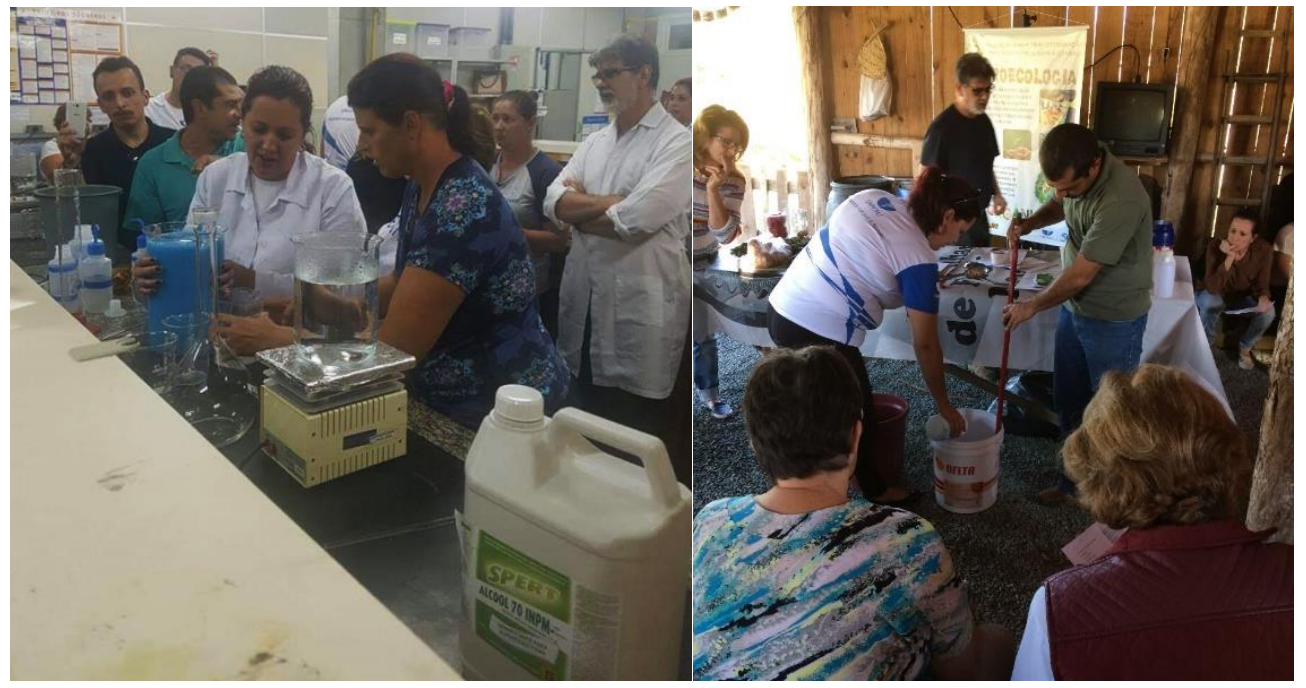

Figura 2 e 3: Preparo de Bioinceticida de Calda Bordalesa em Oficinas com as Mulheres Agricultoras. Fonte: Arquivo pessoal do autor.

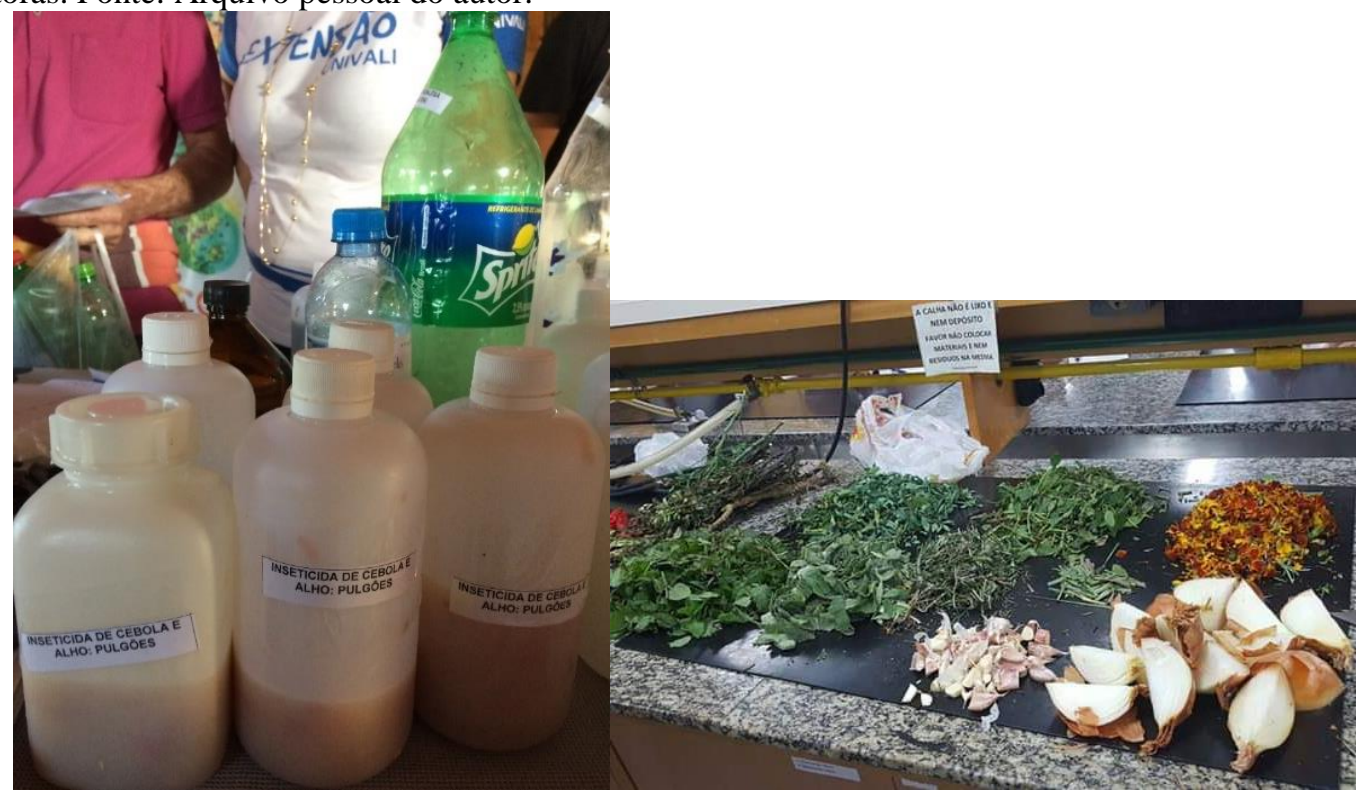

Figura 4 e 5: Bioinceticida de Cebola e Alho produzido durante as Oficinas com as Mulheres Agricultoras. Fonte: Arquivo pessoal do autor. 
$\mathrm{Na}$ oficina de preparação de bioinseticidas foi levantada uma nova temática pelo público-alvo: "Como identificar as doenças nas plantas e o bioinseticida adequado". Tal técnica foi denominada "Controle Biológico". Os danos, as alterações e as doenças podem ser provocadas por insetos ou outros animais, bactérias, vírus, fungos, fatores climáticos, plantas parasitas, dentre outras causas.

A Oficina ocorreu na propriedade de uma agricultora, no Bairro Arraial dos Cunha, participantes dessa oficina figura 02, sendo ministrada novamente pelo Coordenador da Rede Ecovida, para dar continuidade à formação. Foi solicitado que as mulheres agricultoras levassem as plantas que estavam doentes, de suas propriedades, com a finalidade de identificar a doença e encontrar uma solução.

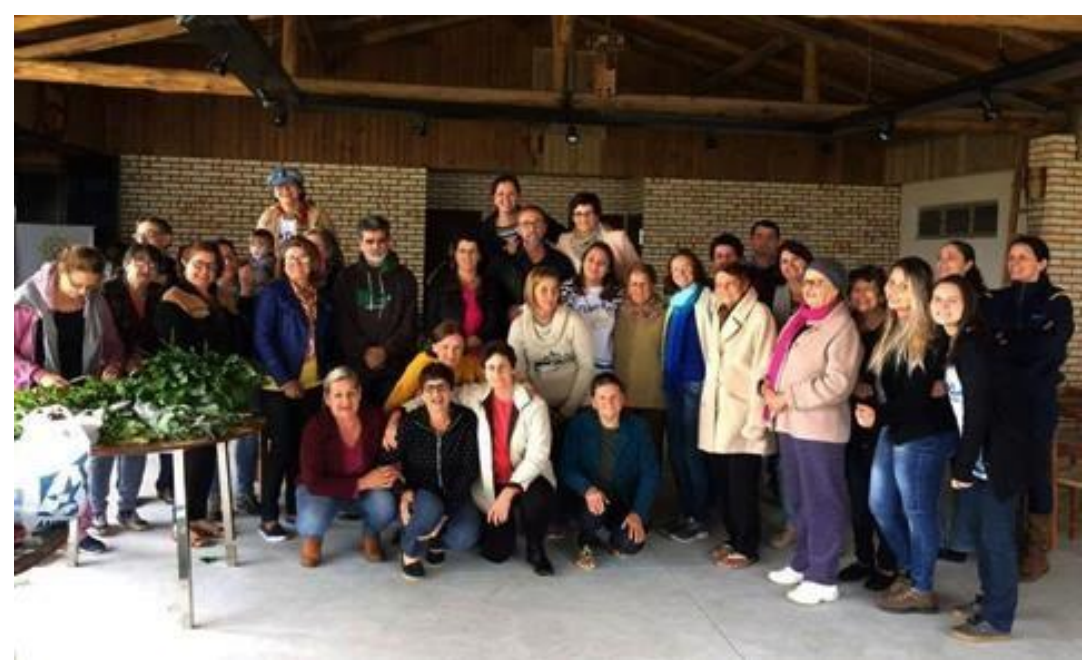

Figura 6: Participantes da Oficina "Controle Biológico", na casa de uma das agricultoras. Fonte: Arquivo pessoal do autor.

Inicialmente, foi realizada uma parte teórica, e apresentadas algumas imagens como modelos de doenças em plantas. Em seguida, pediram para deixar as plantas sobre uma mesa, a fim de que fossem identificadas as doenças e realizadas as indicações para solucionar os possíveis problemas; e para consultas posteriores, foi confeccionada mais uma cartilha abordando o controle biológico.

Dando continuidade, realizou-se a oficina para Gestão de Marketing para Produtos Agroecológicos, com o fito de capacitar as mulheres agricultoras, bem como os integrantes do Projeto à gestão de marketing de seus produtos. Os pontos importantes apresentados pelas mulheres agricultoras foram a realização da gestão de seus produtos, enfatizando que o preço desses alimentos é superior ao preço dos alimentos normais, 
mas a tendência é que isso mude, uma vez que a produção e o consumo levam a um aumento progressivo.

Entre os pontos abordados, foram fomentados os elementos que devem conter nos produtos, sendo eles: a etiqueta de certificação orgânica, os ingredientes contidos no produto, como também a data de validade. Além disso, foram apresentados os passos para a elaboração do custo do produto: a mão de obra, o tempo, os ingredientes, a embalagem, a energia e o gás dispendiosos para o seu preparo.

Ainda foram apresentados os métodos para a divulgação e a promoção dos produtos aos consumidores, como a embalagem do produto, que deve ser atrativa, a recepção e atenção do vendedor na hora de atender o consumidor e a qualidade do produto que está sendo comercializado. É importante ressaltar esses pontos, pois essas são as qualidades básicas de gestão de produtos, e para as mulheres é fundamental esse conhecimento, já que assim conseguem atingir um número maior de clientes.

As feiras são os mais antigos espaços de comercialização existentes que ainda resistem no tempo; elas são encontradas tanto nos vilarejos e pequenos municípios, nos quais observamos os agricultores familiares comercializando suas próprias produções, como nos grandes centros urbanos, onde aqueles foram, em grande parte, substituídos por feirantes/comerciantes que adquirem produtos das Centrais de Abastecimento do Estado de Santa Catarina - CEASA para comercializá-los nas feiras livres. Nas grandes cidades, podemos encontrar também feiras de produtos orgânicos, com produtos alimentícios "in natura" ou beneficiados, vendidos pelos agricultores familiares ou representantes que buscam praticar um preço mais justo para todos os elos da cadeia de produção (Instituto Kairós, 2011).

Nessa perspectiva, as mulheres realizam feiras mensais em parceria com a Incubadora Tecnológica de Cooperativas Populares (ITCP), com as Feiras de Universitaria EcoSolidária para comercializar os seus produtos. Assim, essa oficina veio como agente motivador e transformador para as mulheres agricultoras, as quais tiveram a oportunidade de aprender como realizar a gestão dos produtos que comercializam nas feiras.

O Projeto trouxe uma temática inovadora - as Plantas Alimentícias Não Convencionais (PANC) - contemplando as mulheres agricultoras e também os participantes do Grupo de Estudos Interdisciplinares em Agroecologia (GEIA) por meio 
de uma oficina que aconteceu dentro da Universidade, em parceria com a EPAGRI, e teve por objetivo introduzir essa temática e sua importância. Essa oficina motivou a equipe a realizar uma visita ao Sítio Flora Bioativa para compreender o manejo e o funcionamento dessas plantas. E como encerramento das atividades do ano de 2017, o Projeto promoveu uma oficina tratando dessa temática, PANC, pela qual objetivou introduzir o consumo desses alimentos na vida das mulheres e dos acadêmicos como uma nova possibilidade de segurança alimentar.

As PANC são plantas que possuem uma ou mais partes que podem ser utilizadas diretamente na alimentação humana, tais como: raízes tuberosas, tubérculos, bulbos, rizomas, cormos, talos, folhas, brotos, flores, frutos e sementes ou ainda látex, resina e goma, ou indiretamente quando são usadas para obtenção de óleos e gorduras alimentícias (Kinupp; Lorenzi, 2014).

Outra temática debatida com as mulheres e os acadêmicos foram os Sistemas Agroflorestais (SAFs), os quais são de uso da terra em que as árvores interagem com os cultivos agrícolas, frutícolas e/ou animais, simultânea ou sequencialmente, de modo a aumentar a produtividade total de plantas e animais de forma sustentável por unidade de área (Alves; Laura; Almeida, 2015, p18).

Essa Oficina foi promovida dentro da UNIVALI, e contou com uma parte teórica e uma parte prática. No primeiro momento, foram passadas algumas informações básicas de como funcionavam os Sistemas Agroflorestais (SAFs), enfatizando a sua importância econômica e ambiental, e em seguida, mostrou-se quais plantas eram boas para ser utilizadas. Após a teoria, os participantes se dirigiram para a Horta Orgânica Experimental - Ibyporã, onde realizaram a construção de um canteiro no modelo de sistema agroflorestal.

Realizou-se ainda a Oficina com a temática de Plantas Medicinais, desenvolvida na UNIVALI, e teve como objetivo proporcionar aos participantes conhecimento teórico e prático sobre as plantas medicinais com enfoque na sustentabilidade. Esta Oficina contou com a apresentação dos acadêmicos da disciplina de Química Orgânica e da Coordenadora do Projeto de Extensão, sendo o primeiro momento, teórico. Após, os participantes se dirigiram ao Laboratório de Fitoterapia da UNIVALI, local em foi ministrada a parte prática da Oficina por uma especialista na área.

Essa oficina foi importante para dar continuidade à formação de conhecimentos 
dos acadêmicos e das mulheres agricultoras, que tiveram a oportunidade de aprender sobre as plantas medicinais e seus benefícios à saúde. Na parte teórica, foram apresentadas informações pertinentes sobre algumas plantas e quais eram as suas funcionalidades em cada sistema do corpo humano. A parte prática contou com pequenas oficinas, tendo 04 práticas diferentes acontecendo ao mesmo tempo: Infusão de plantas medicinais e degustação; extração de óleos essenciais; produção de tinturas; identificação de plantas medicinais.

Essa oficina resgatou conhecimentos populares utilizados pelas mulheres agricultoras, possibilitando um maior conhecimento acerca da origem dos saberes e das práticas sobre o uso terapêutico das plantas medicinais. Pode-se constatar que o uso de plantas medicinais, na maioria das vezes, originárias do meio familiar, e seu poder curativo, assume grande valor na vida mulheres, sendo seu conhecimento transmitido de geração para geração. A influência da mulher ganha enorme relevância na transmissão desse conhecimento, e incentivo para o cultivo de plantas medicinais, assim como o sentimento de querer dar continuidade a essa prática complementar de cuidado à saúde.

Comparando o saber popular com o saber científico sobre a eficácia farmacológica das plantas medicinais, observou-se que ocorre uma aproximação entre os dois, até porque a grande maioria dos vegetais apresenta suas indicações terapêuticas confirmadas em estudos científicos.

As plantas medicinais, que têm avaliadas as suas eficiências terapêuticas e a segurança do uso, dentre outros aspectos, estão cientificamente aprovadas a serem utilizadas pela população nas suas necessidades básicas de saúde, em função da facilidade de acesso, do baixo custo e da compatibilidade com o resgate cultural com as tradições populares. Uma vez que as plantas medicinais são classificadas como produtos naturais, a lei permite que sejam comercializadas livremente, além de poderem ser cultivadas por aqueles que disponham de condições mínimas necessárias. (Rodrigues, 2004)

O Projeto realizou a oficina de Hortas Urbanas na UNIVALI, as hortas urbanas visam melhorar a alimentação das pessoas envolvidas na Tecnologia Social Hortas Urbanas, beneficiando o ambiente como um todo e favorecendo a relação da comunidade com o bairro e o seu entorno, por meio do cultivo ecológico de alimentos e ervas medicinais em hortas, jardins, canteiros suspensos e outras possibilidades, 
conforme a realidade do local (Instituto Pólis, 2017).

Essa oficina contou com uma parte teórica, pela qual foram introduzidos os conceitos importantes sobre hortas urbanas, os benefícios de aplicar essa prática e alguns modelos que já existem e são bem-sucedidos. Após, deu-se início a parte prática, momento em que foi construído um canteiro na horta orgânica experimental simulando uma horta urbana. Essas vivências em temáticas diferentes, são importantes para o público-alvo, pois estimulam a busca por novos conhecimentos, incentivando o aprimoramento das técnicas utilizadas em suas hortas.

Devido à demanda crescente de mulheres agricultoras em assuntos relacionados a produção orgânica, a equipe do Projeto criou uma rotina de visitas de assistência técnicas nas propriedades para conhecer cada participante. Ao todo foram 23 visitas de assistência técnicas realizadas, no ano de 2017, nas propriedades das mulheres agricultoras num período de 09 meses. O intuito principal é solucionar, de maneira pontual, as dificuldades das agricultoras e observar o desempenho dos seus cultivos, além de auxiliá-las na realização de diversas atividades importantes para a transição agroecológica, como a construção de composteiras de leira, Bokashi, preparação de bioinseticidas e de canteiros elevados.

Além disso, nas visitas são aplicados questionários semiestruturados para manter os dados atualizados, que contemplam algumas perguntas relacionadas ao processo de transição agroecológica, o rendimento da produção e os fatores econômicos, além do estado em que a propriedade se encontra, bem como a saúde das mulheres agricultoras. Essas perguntas são importantes para aproximar o público, trazendo uma sensação de conforto.

A equipe do Projeto organizou visitas técnicas às propriedades de agricultores agroecológicos que possuem Certificação Orgânica, com o intuito de auxiliar na construção dos conhecimentos científicos relacionados à agricultura sustentável. Essas atividades, em ambientes ecologicamente sustentáveis, envolvem e motivam, tendo em vista que ampliam os saberes adquiridos nas Oficinas; além disso, promovem uma mudança de valores e uma postura em relação à prática de comercialização de produtos agroecológicos dentro da política de economia solidária.

As visitas técnicas realizadas foram: a) Visita Técnica ao Sítio Flora Bioativas, Porto Belo/SC, onde foi realizada uma caminhada pela propriedade para identificar e 
aprender as funções das Plantas Alimentícias Não Convencionais (PANC) e de Plantas Medicinais; b) Visita Técnica ao Sítio Flor de Ouro, Ratones/SC, onde se teve a oportunidade de aprender sobre o Sistema Agroflorestal, que reúne as culturas de importância agrônoma em consórcio com a floresta; c) Visita Técnica à EPAGRI, que contou com uma primeira parte teórica para a apresentação dos projetos desenvolvidos no espaço agroecológico da EPAGRI, e em seguida, foi realizada uma saída para conhecer a área de cultivo. Além disso, as mulheres tiveram a oportunidade de conhecer a máquina que auxilia na compostagem. Observou-se que essa máquina revira o composto, sem ser necessário o trabalho manual; d) Visita Técnica à reunião mensal da Rede Ecovida em Joinville, que mostrou o funcionamento da Certificação Participativa e como acontecia uma reunião do Núcleo da Rede Ecovida.

Uma outra estratégia utilizada diz respeito às rodas de conversa, na qual os participantes problematizaram, refletiram, buscaram soluções e trocaram conhecimentos. Dentro dessa perspectiva, o Projeto de Extensão participou pelo segundo ano, na Biblioteca Central da UNIVALI, da exposição sobre a Promoção da Alimentação Saudável, enfatizando os agrotóxicos e seus malefícios à saúde e ao ambiente. Além disso, realizou uma roda de conversa, na qual foi abordada a importância do processo de transição agroecológica na vida das mulheres agricultoras de Itajaí/SC, bem como seu empoderamento e sua autonomia.

Também foram realizadas rodas de conversa, com intuito de multiplicar os saberes agroecológicos para mulheres rurais de localidades diferentes. O Projeto realizou uma roda no evento do Programa Saúde da Mulher Rural, organizado pela Prefeitura de Araquari; essa roda contou com a presença de agricultoras participantes do Projeto, e que relataram sobre a vivência no processo de transição agroecológica, para outras trabalhadoras rurais. Nessa ocasião, elas tiveram a oportunidade de conhecer essa possibilidade de cultivar alimentos saudáveis sem precisar contaminar o ambiente e, principalmente, a saúde da sua família e das pessoas que consomem os produtos.

No prosseguir do trabalho, foi realizada uma roda de conversa com um grupo de hipertensos da Estratégia da Saúde, na Comunidade de Espinheiros em Itajaí-SC e que teve como intuito promover discussões relacionadas ao consumo de uma alimentação saudável e os malefícios dos agrotóxicos para a saúde das pessoas. Nessa ocasião, as pessoas puderam conhecer sobre as Plantas Alimentícias não Convencionais (PANC) e 
desmistificar a ideia da dificuldade de produzir alimentos orgânicos.

Outra Roda foi realizada na Semana da Alimentação e que aconteceu em Florianópolis, com um público bastante diversificado, que contou com a apresentação da história do Projeto, a importância que ele possui na vida das mulheres agricultoras e ainda proporcionou um momento de trocas de experiências com os depoimentos das mulheres agricultoras que estavam presentes, o que gerou uma reflexão sobre as temáticas levantadas, e o quanto essa metodologia consegue transformar o modo de pensar dos participantes.

Foi realizada uma Visita Técnica ao Sítio Flora Bioativas, Porto Belo/SC, com todos os integrantes do Projeto e as mulheres que dele participam ativamente. $\mathrm{Na}$ primeira atividade, utilizou-se a Roda de conversa, figura 03, onde a proprietária realizou momentos de trocas de saberes e experiências sobre o dia a dia do funcionamento do espaço, contou um pouco sobre sua história e como é estar consolidada na agroecologia. Também falou sobre PANC (que é sua especialidade no sítio), mostrou a aplicação, enfatizando os benefícios à saúde e depois finalizou falando sobre a certificação dos alimentos orgânicos. Essas temáticas abordadas foram de suma importância no processo da formação de conhecimentos.

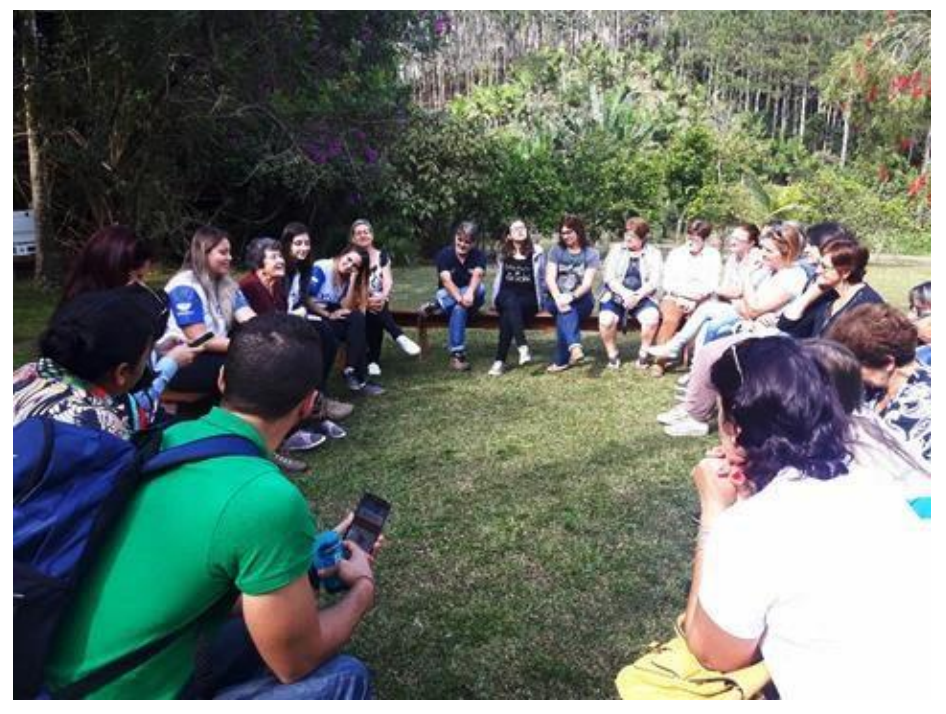

Figura 7: Roda de conversa realizada no Sítio Flora Bioativas. Fonte: arquivo pessoal do autor.

Para finalizar, ainda pode-se constatar na última roda realizada "Mulheres Agricultoras: autonomia e empoderamento" a verdadeira "autonomia e empoderamento" nas falas dessas mulheres, isso fez com que todos os participantes percebessem a força que existe nas trabalhadoras rurais e a transformação dentro da 
agroecologia, figura 04 .

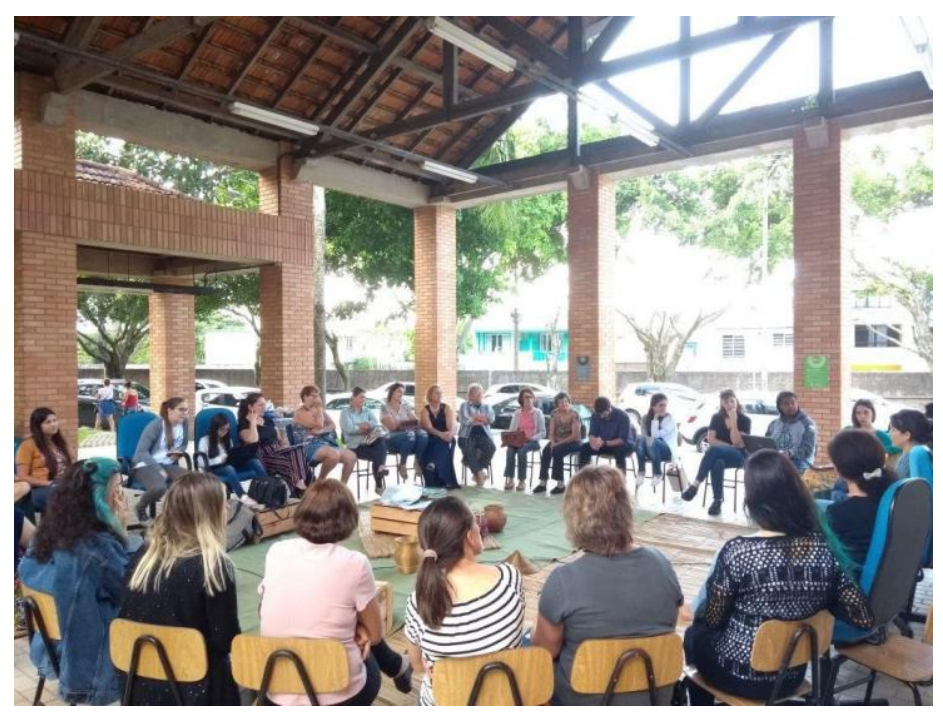

Figura 8: Roda de conversa realizada na UNIVALI. Fonte: arquivo pessoal do autor.

As rodas de conversa, metodologia bastante utilizada nos processos de leitura e intervenção comunitária, consistem em um método de participação coletiva de debates acerca de uma temática, por meio da criação de espaços de diálogo, nos quais os sujeitos podem se expressar e, sobretudo, escutar os outros e a si mesmos. Tem como principal objetivo motivar a construção da autonomia dos sujeitos, por meio da problematização, da socialização de saberes e da reflexão voltada para a ação. Envolve, portanto, um conjunto de trocas de experiências, conversas, discussão e divulgação de conhecimentos entre os envolvidos nesta metodologia (Nascimento; Silva, 2009).

Para Ohira (2002), os eventos científicos são meios altamente eficientes na comunicação oral do conhecimento, visto o ritmo crescente do desenvolvimento da ciência e, portanto, um meio de divulgação e assimilação de novos conhecimentos. Neste contexto, o projeto oportuniza para as mulheres agricultoras e para os acadêmicos a participação em eventos científicos de escala regional e nacional, cuja finalidade é a de proporcionar uma visão mais ampla de conhecimento e disseminar o trabalho realizado pelo Projeto, por meio da produção de materiais científicos e relatos de experiência.

\section{CONSIDERAÇÕES FINAIS}

A importância de realizar um Projeto na região rural do município de Itajaí, Santa Catarina, cuja principal força econômica é caracterizada pela agricultura familiar, 
permitiu a compreensão das dificuldades enfrentadas cotidianamente. Diante disso, surgiu a necessidade de uma intervenção no modo de produção e de organização das mulheres agricultoras, visando à adaptação das técnicas de manejo sustentável de base agroecológica, em conjunto com a formação de um grupo organizacional, obtendo uma melhor resposta para a luta pela autonomia social, política e cultural das mulheres do grupo, além de estimular a participação cidadã como estratégia de mudança.

A comercialização dos produtos oriundos da agricultura familiar, inquestionavelmente expressa um grande desafio. Frente a isso, a formação do grupo de agricultoras e a formalização da participação do grupo de mulheres na Rede Ecovida de Agroecologia, articulada pelo objetivo do cooperativismo, vem para solucionar esses desafios, auxiliando na elaboração de mecanismos para a viabilidade social e econômica da cadeia produtiva dos produtos orgânicos produzidos de base agroecológica.

A partir da temática abordada, nota-se do ponto de vista politizado, a compreensão pela necessidade da luta pela ampliação, aplicação, qualificação e consolidação de políticas públicas para a manutenção de resultados econômicos e sociais efetivos na agricultura familiar, mediante os princípios instituídos por modelos descentralizados. É primordial o fortalecimento da Política Nacional de Resíduos Sólidos, no âmbito de valorização da fração orgânica, visando manter a ciclagem de nutrientes no sistema em ciclos "fechados", quanto possível, a fim de alcançar características semelhantes àquelas dos ecossistemas naturais. $\mathrm{O}$ aprimoramento do formato do Programa de Aquisição de Alimentos (PAA) e a ampliação e qualificação da alimentação escolar, pelo Programa Nacional de Alimentação Escolar do Ministério da Educação (Pnae/MEC) conferem um avanço no acesso ao mercado institucional, garantindo a viabilidade econômica a partir da produção.

Com essa ação, o Projeto visa ampliar as fronteiras entre a Universidade e a comunidade, trazendo soluções diárias para a vida da população, fortalecendo esses elos entre a teoria científica e a aplicação das práticas. Relatos de agricultoras têm fomentado o anseio da ampliação do Projeto, alcançando toda a população e trazendo benefícios a toda sociedade. Segundo depoimentos das agricultoras, o Projeto tem proporcionado uma mudança na qualidade de vida, inclusão e autonomia das mulheres no mercado, valorização do trabalho camponês e familiar, saúde e bem-estar, além da pretensão de adquirir mais conhecimentos, e aumento de um suplemento de receita 
familiar.

\section{REFERENCIAS}

ALMEIDA V.E.S.; et al. Use of Genetically Modified Crops and Pesticides in Brazil: Growing Hazards. Cien Saúde Colet [periódico na internet] (2017/Jul). Disponível em: $<$ http://www.cienciaesaudecoletiva.com.br/artigos/use-of-genetically-modified-cropsand-pesticides-inbrazil-growing-hazards/16307?id=16307>. Acessado em: nov 2017.

ALVES, F. V.; LAURA, V. A.; ALMEIDA, G. R (Editores tec). Sistemas Agroflorestais: a agropecuária sustentável. Brasilia: EMBRAPA, 2015.

BERNAL, A. B. (Org.). Apoio à implementação do Programa de educação ambiental e agricultura familiar nos territórios. Sustentabilidade e agroecologia: conceitos e fundamentos. Brasília: MMA, v.3, 96p, 2015.

BRASIL. Relatório Nacional de Vigilância em Saúde de Populações Expostas a Agrotóxicos. Brasília: Ministério da Saúde, 2016.

BRASIL, Lei. 11.326, de 24 de julho de 2006: Estabelece as diretrizes para a formulação da Política Nacional da Agricultura Familiar e Empreendimentos Familiares Rurais. Diário Oficial da União, Brasília, 2006. Disponível em:

<http://www.planalto.gov.br/ccivil_03/_ato2004-2006/2006/lei/111326.htm >. Acessado em> set. 2017.

BRASIL. Lei 12.305 de 02 de agosto de 2010: Institui a Política Nacional de Resíduos Sólidos; altera a Lei no 9.605 de 12 de fevereiro de 1998; e dá outras providências. Diário Oficial da União, Brasília: 2011. Disponível em:

<http://www.sinir.gov.br/web/guest/plano-nacional-de-residuos-solidos >. Acessado em: set. 2017.

CARSON, R. Primavera Silenciosa. Tradução de Cláudia Sant'Anna Martins. São Paulo: Portico, 1969.

CARNEIRO, F. F. et al; (Org). Dossiê ABRASCO: um alerta sobre os impactos dos agrotóxicos na saúde. Rio de Janeiro: EPSJV; São Paulo: Expressão Popular, 2015.

FERREIRA, G. H. Agroecologia: caminho de preservação do agricultor e do meio ambiente. Revista GeoPantanal, v. 10, n. 18, p. 237-242, 2015.

FREIRE, P. Educação como prática de liberdade. 20. ed. Rio de Janeiro: Paz e Terra, 1991.

Pedagogia do oprimido. Rio de Janeiro: Paz e Terra, 1983.

GADOTTI, M. Convite a Leitura de Paulo Freire. São Paulo: Scipione, 1991.

GREENPEACE BRASIL. Agricultura Tóxica: um olhar sobre o modelo agrícola 
Brasileiro. São Paulo: Greenpeace Brasil, 2017.

INSTITUTO KAIRÓS; BADUE, A. F. B.; GOMES, F. F. F. Caminhos para Práticas de Consumo Responsável: parceria entre consumidores e produtores na organização de feiras. São Paulo: [s.n.], 2011.

INSTITUTO PÓLIS. Hortas Urbanas: moradia urbana com tecnologia social. [s.1.]: Fundação Banco do Brasil, 2017.

KINUPP, V. F.; LORENZI, H. Plantas Alimenticias Não Convencionais (PANC) no Brasil: guia de identificação, aspectos nutricionais e receitas ilustradas. São Paulo: Instituto Plantarum de Estudos da Flora, 2014.

\section{NASCIMENTO, M. A. G.; SILVA, C. N. M. RODAS DE CONVERSA E} OFICINAS

TEMÁTICAS: experiências metodológicas de ensino-aprendizagem em geografia. Porto Alegre: ENPEG, 2009.

PRETTY J.; MORRISON J. I. L.; HINE R. E. "Reducing Food Poverty by Increasing Agricultural Sustainability in Developing Countries," Agriculture, Ecosystems and Environment 95, p. 217-34, 2003.

REDE DE AGROECOLOGIA ECOVIDA. Caderno de Formação: Certificação Participativa de produtos ecológicos. Florianópolis: Rede Ecovida de Agroecologia, 2004, 48 p.

RODRIGUES, V. G.S. Cultivo, uso e manipulação de plantas medicinais. Porto Velho: Embrapa Rondônia, 2004.

ROSENZWEIG C.; HILLEL D. Climate Change and the Global Harvest: Impacts of El Nino and Other Oscillations on Agroecosystems. New York: Oxford University Press, 2008.

OHIRA, M. L. B.; PRADO, N. S. Bibliotecas virtuais e digitais: análise das comunicações em eventos científicos (1995/2000). Ciência da Informação, Brasília: v.31, n.1, jan. 2002.

OLIVEIRA, D. ;SANTOS, L. C. R. (COORD.). CADERNO de formação: certificação participativa de produtos ecológicos. Florianópolis: Rede Ecovida de Agroecologia, 2004, 48 p.

\section{TEIXEIRA et al. PROCESSO DE COMPOSTAGEM, A PARTIR DE LIXO ORGÂNICO URBANO, EM LEIRA ESTÁTICA COM VENTILAÇÃO}

NATURAL. Belém: Circular. Técnica 33, 2004. Disponível em: < https://ainfo.cnptia.embrapa.br/digital/bitstream/item/28113/1/Circ.tec.33.pdf>. Acessado em: set 2018. 
olhar sobre a prática. Rio de Janeiro: Ibase, 2011.

VIEIRA, M. G. M, et al. Educação para Transformação: meio ambiente, saúde e gênero. Rev. Ed. Popular: Uberlândia. v. 15, n. 1, p. 180-193, jan./jun. 2016. Disponivel em: < http://www.seer.ufu.br/index.php/reveducpop/article/view/32559>. Acessado em: out 2018.

VIEZZER, M; (Org.). Autonomia Econômica e Igualdade no Mundo do Trabalho, com Inclusão Social: reconhecendo e valorizando as mulheres. Toledo: Instituto de Comunicação Solidária, 2009. 